\title{
On a report that the $2012 M 6.0$ earthquake in Italy was predicted after seeing an unusual cloud formation
}

\author{
J. N. Thomas ${ }^{1,2,3}$, F. Masci $^{4}$, and J. J. Love ${ }^{5}$ \\ ${ }^{1}$ NorthWest Research Associates, Redmond, Washington, USA \\ ${ }^{2}$ Department of Electrical and Computer Engineering, DigiPen Institute of Technology, Redmond, Washington, USA \\ ${ }^{3}$ Department of Earth and Space Sciences, University of Washington, Seattle, Washington, USA \\ ${ }^{4}$ Istituto Nazionale di Geofisica e Vulcanologia, L'Aquila, Italy \\ ${ }^{5}$ Geomagnetism Program, U.S. Geological Survey, Denver, Colorado, USA
}

Correspondence to: J. N. Thomas (jeremy@nwra.com)

Received: 17 April 2014 - Published in Nat. Hazards Earth Syst. Sci. Discuss.: 10 September 2014

Accepted: 4 May 2015 - Published: 27 May 2015

\begin{abstract}
Several recently published reports have suggested that semi-stationary linear-cloud formations might be causally precursory to earthquakes. We examine the report of Guangmeng and Jie (2013), who claim to have predicted the 2012 M6.0 earthquake in the Po Valley of northern Italy after seeing a satellite photograph (a digital image) showing a linear-cloud formation over the eastern Apennine Mountains of central Italy. From inspection of 4 years of satellite images we find numerous examples of linear-cloud formations over Italy. A simple test shows no obvious statistical relationship between the occurrence of these cloud formations and earthquakes that occurred in and around Italy. All of the linearcloud formations we have identified in satellite images, including that which Guangmeng and Jie (2013) claim to have used to predict the 2012 earthquake, appear to be orographic - formed by the interaction of moisture-laden wind flowing over mountains. Guangmeng and Jie (2013) have not clearly stated how linear-cloud formations can be used to predict the size, location, and time of an earthquake, and they have not published an account of all of their predictions (including any unsuccessful predictions). We are skeptical of the validity of the claim by Guangmeng and Jie (2013) that they have managed to predict any earthquakes.
\end{abstract}

\section{Introduction}

The old notion that earthquakes might be preceded by peculiar weather has recently been seemingly supported by several reports that unusual cloud formations might be causally precursory to earthquakes. Many of these reports have identified linear arrangements of clouds that seem to persist for several hours in a more or less stationary location near earthquake epicenters. For example, Shou (1999) reported linear-cloud formations 32 days prior to the $17 \mathrm{Au}$ gust 1997 M7.4 Izmit, Turkey earthquake and 30 days prior to the 4 February 1998 M5.9 Afghanistan earthquake. Shou (2006) reported linear-cloud formations 5 days prior to the 26 December 2003 M6.6 Bam, Iran earthquake. Guo and Wang (2008) reported linear-cloud formations 69 days prior to the 22 February 2005 M6.4 Zarand, Iran earthquake and 64 days prior to the 28 February 2006 M6.0 Tiab, Iran earthquake. Wu et al. (2009) reported-linear cloud formations prior to the 12 May 2008 M7.9 Wenchuan, China earthquake.

More recently, after identifying linear-cloud formations in infrared satellite images, Guangmeng and Jie (2013) predicted three earthquakes before their occurrences, and they communicated their predictions with colleagues prior to their occurrences. Similar to reports by other investigators, Guangmeng and Jie described the clouds as being linearly arranged above and near geological faults, and unmoving or stationary relative to these formations for hours; that is, they 
were not advected away by wind. In the case of an Italy earthquake, Guangmeng and Jie observed linear cloud formations on 22-23 April 2012. On the basis of this observation, they predicted that an earthquake would occur somewhere in Italy: either M5.5-6.0 within "about" 10 days or if M6.0 in 30 days. They did not give any specific bounds on epicenter or hypocenter location, and they did not give any expression of statistical confidence for their prediction. Nonetheless, it might be interesting that an $M 6.0$ earthquake actually occurred 30 days later on 20 May 2012 in northern Italy (epicenter $44.80^{\circ} \mathrm{N}, 11.19^{\circ} \mathrm{E}$ ). For two Iran earthquakes, they observed clouds on 19-20 February 2012, a week prior to an M5.1 earthquake on 27 February, and they observed clouds on 1 March 2012, a week prior to an M5.1 earthquake on 8 March.

Reports of precursory cloud formations have, in turn, motivated the development of physical theories (e.g., Freund et al., 2009; Harrison et al. 2014). And, indeed, if cloud formations could be reliably correlated with impending seismic activity, this would, as Guangmeng and Jie assert (2013, p. 95), certainly be an important development for the science of earthquake prediction. Our concern, however, is that the evidence for precursory cloud formations appears to be vague, anecdotal, of unknown validity, and, so far, unverified in any rigorous way by independent researchers. We are, therefore, motivated to examine the claim by Guangmeng and Jie that earthquakes are sometimes preceded by unusual cloud formations.

\section{Many clouds and many earthquakes}

We focus our examination on the report by Guangmeng and Jie (2013) that precursory linear-cloud formations were realized over an earthquake fault in Italy prior to the occurrence of an earthquake. We obtain the same infrared satellite images that Guangmeng and Jie obtained from the Meteo Company SAT24, but instead of simply focusing on a short duration of time before the 20 May 2012 M6.0 earthquake, as Guangmeng and Jie did, we examine 4 years of satellite images (January 2010-December 2013). In Fig. 1, we summarize our identification of 24 separate instances of linearcloud formations over Italy, each selected independently of any seismic activity. These are enlarged views of the original satellite images and show linear-cloud formations along different regions of the Apennine Mountain range in Italy. And we note that the linear-cloud formation identified by Guangmeng and Jie as possibly precursory to the 20 May 2012 Italian earthquake, 22 April 2012, is just 1 of the 24 examples shown in Fig. 1. The resolution of the infrared SAT24 images is 72 pixels/inch, and they are available every $15 \mathrm{~min}$. We examined one image per hour for linear-cloud formations. Table 1 lists appearance and disappearance times for instances of linear-cloud formations over Italy during January 2010 December 2013. To show how these clouds were formed and
Table 1. Instances of linear-cloud formations that occurred over Italy during 2010-2013.

\begin{tabular}{|c|c|c|c|}
\hline Date & Year & $\begin{array}{l}\text { Approximate } \\
\text { appearance } \\
\text { time (UTC) }\end{array}$ & $\begin{array}{l}\text { Approximate } \\
\text { disappearance } \\
\text { time (UTC) }\end{array}$ \\
\hline 8 Jun & 2011 & 01:00 & 08:00 \\
\hline $5 \mathrm{Dec}$ & 2011 & 07:00 & 23:00 \\
\hline $14 \mathrm{Dec}$ & 2011 & 01:00 & 19:00 \\
\hline $15 \mathrm{Dec}$ & 2011 & 00:00 & $12: 00$ \\
\hline 21-22-23 Apr & 2012 & 20:00 (day 21) & 06:00 (day 23) \\
\hline 5-6 Мay & 2012 & 21:00 (day 5) & 06:00 (day 6) \\
\hline 14 Aug & 2012 & 09:00 & $15: 00$ \\
\hline 17 Aug & 2012 & $11: 00$ & $17: 00$ \\
\hline 24-25 Sept & 2012 & 14:00 (day 24) & 01:00 (day 25) \\
\hline 27 Sept & 2012 & 00:00 & $22: 00$ \\
\hline $14-15$ Oct & 2012 & 22:00 (day 14) & $10: 00$ (day 15$)$ \\
\hline $25 \mathrm{Dec}$ & 2012 & 05:00 & 21:00 \\
\hline $10 \mathrm{Apr}$ & 2013 & 00:00 & $06: 00$ \\
\hline 29 May & 2013 & 07:00 & $16: 00$ \\
\hline 7-8 Aug & 2013 & 22:00 (day 7) & 08:00 (day 8) \\
\hline 10 Oct & 2013 & $12: 00$ & $22: 00$ \\
\hline $13 \mathrm{Oct}$ & 2013 & 00:00 & 06:00 \\
\hline $28-29$ Oct & 2013 & 22:00 (day 28) & $10: 00$ (day 29) \\
\hline $3 \mathrm{Nov}$ & 2013 & 04:00 & $17: 00$ \\
\hline $4 \mathrm{Nov}$ & 2013 & 00:00 & $13: 00$ \\
\hline 9-10 Nov & 2013 & 09:00 (day 9) & 04:00 (day 10) \\
\hline $20 \mathrm{Nov}$ & 2013 & $16: 00$ & $22: 00$ \\
\hline $29 \mathrm{Dec}$ & 2013 & 00:00 & 04:00 \\
\hline
\end{tabular}

their stationary nature over the eastern Apennine Mountain range, in the Supplementary Material we include movies for many of the examples shown in Fig. 1.

Using the online catalog of the National Earthquake Information Center of the U.S. Geological Survey (www. earthquake.usgs.gov), in Table 2 we list the $14 M \geq 5.0$ earthquakes that occurred in and near Italy, within the geographic square of $35-48^{\circ} \mathrm{N}$ latitude and $6-20^{\circ} \mathrm{E}$ longitude, and within the time interval 1 January 2010-31 December 2013. The locations of the earthquakes are shown in the map in Fig. 2. A lower magnitude threshold would lead to the counting of a larger number of events; in the same geographic square for the same duration of time there were 68 earthquake events with $M \geq 4.5$. Such a low threshold was not discussed by Guangmeng and Jie (2013), and so we do not consider it further. Figure 3 shows the times of instances of linear-cloud formations listed in Table 1 and earthquake occurrences listed in Table 2.

\section{Discussion and conclusions}

In order to predict, in any practical sense, the occurrence of an earthquake, it must be possible to clearly associate a possible precursory phenomenon with an impending earthquake. We note, however, that linear-cloud formations, sim- 
(a)
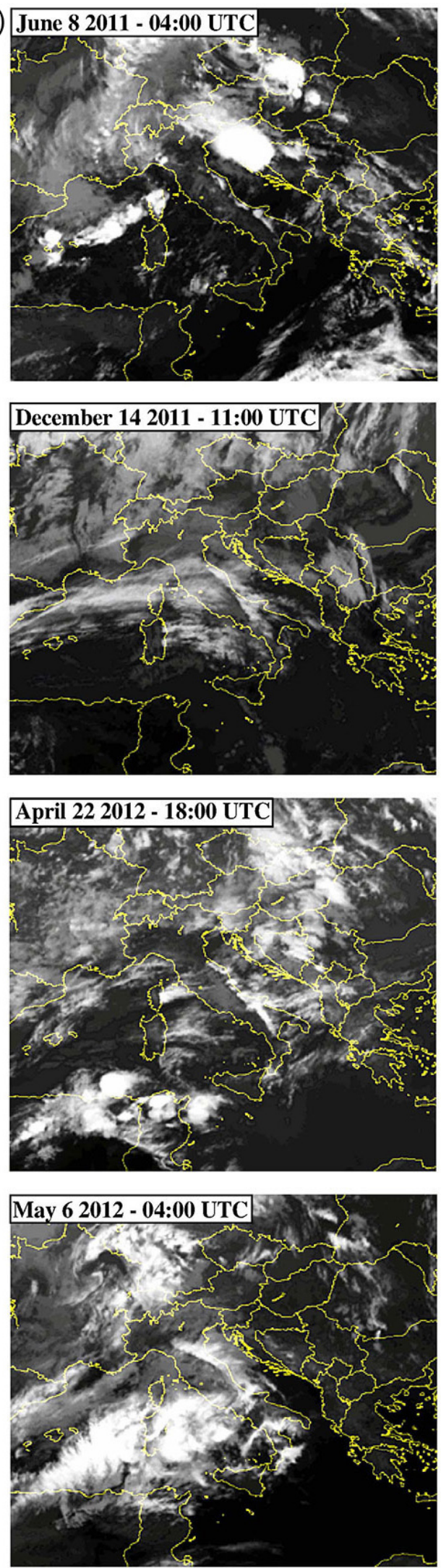
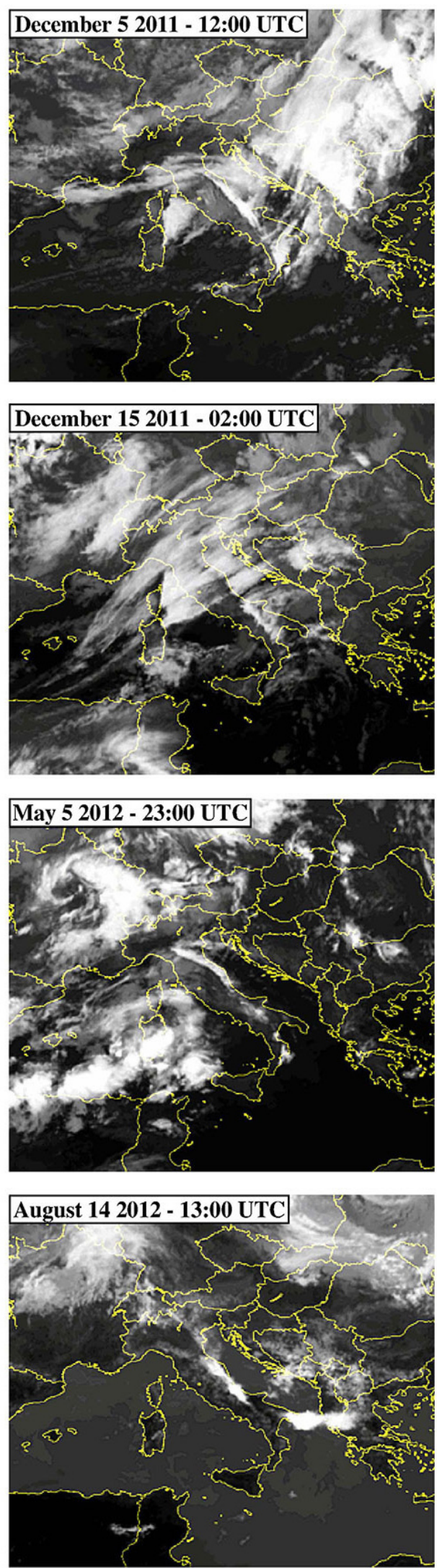

Figure 1. 
(b)
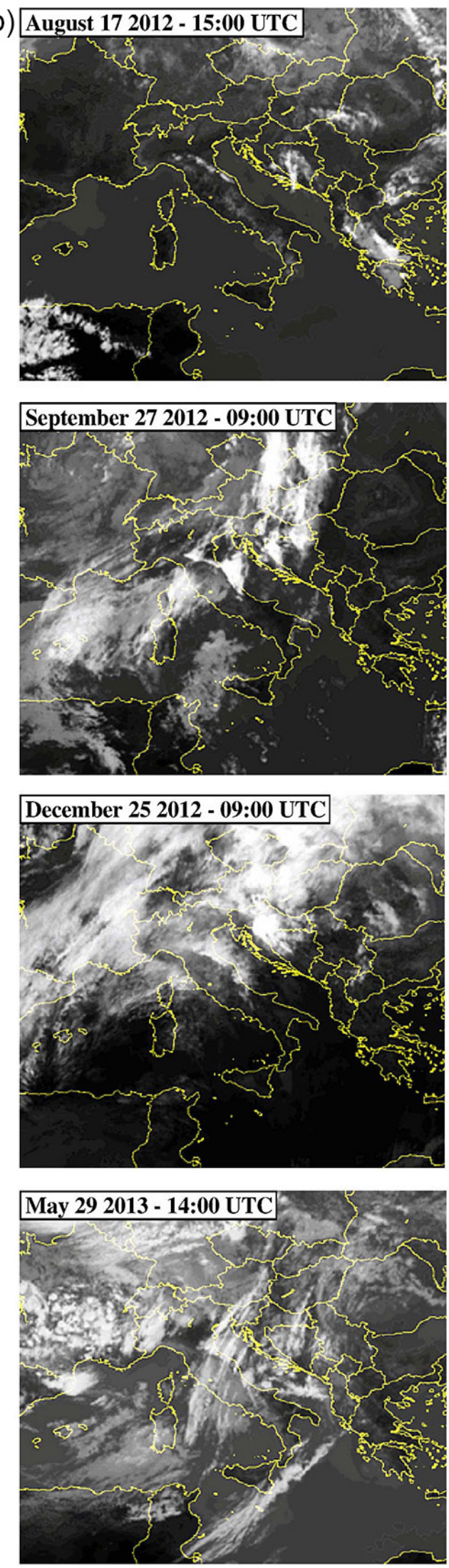
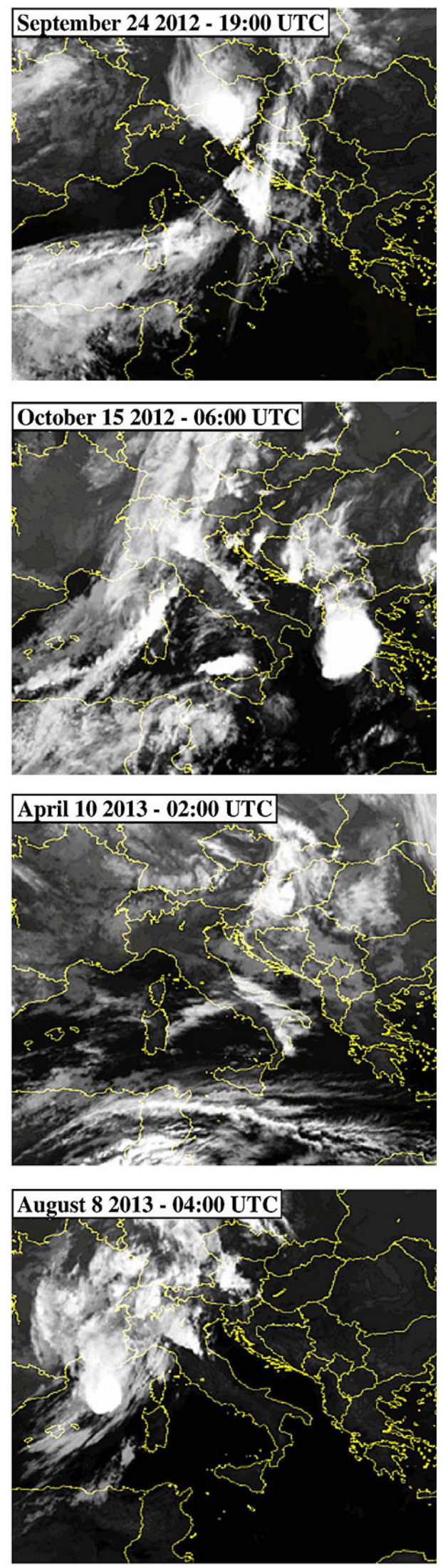

Figure 1. 

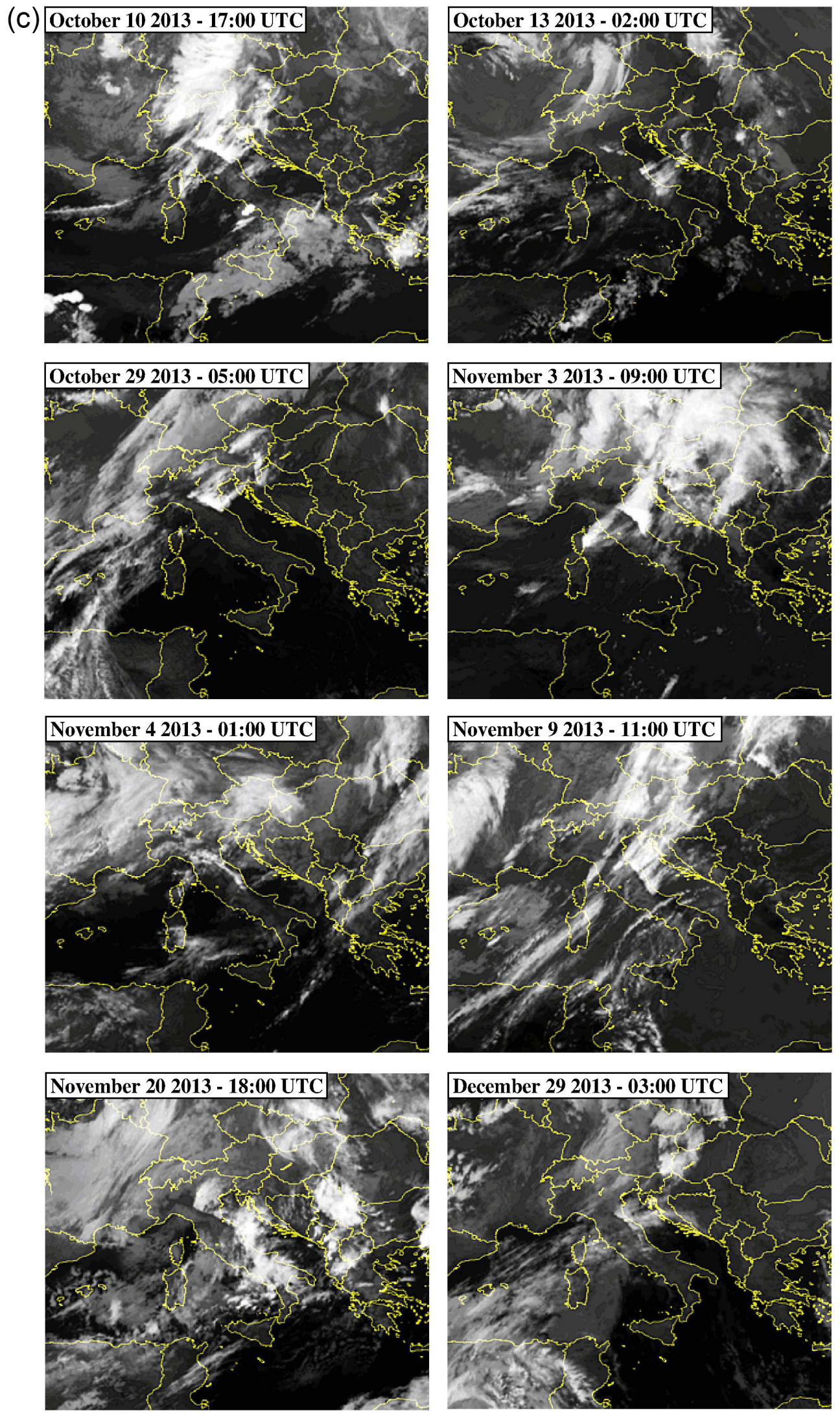

Figure 1. A total of 24 separate examples of linear-cloud formations over Italy (January 2010-December 2013), including the instance for 22 April 2012 that Guangmeng and Jie (2013) claim led them to predict the M6.0 Earthquake on 20 May 2012. 
Table 2. $M \geq 5$ earthquakes that occurred in and near Italy (lat. $35-48^{\circ} \mathrm{N}$, long. 6-20 $\mathrm{E}$ ) during 2010-2013.

\begin{tabular}{lrrrrrr}
\hline Date & Year & Time $(\mathrm{UTC})$ & Lat $\left({ }^{\circ} \mathrm{N}\right)$ & Long $\left({ }^{\circ} \mathrm{E}\right)$ & Depth $(\mathrm{km})$ & $M$ \\
\hline 22 Aug & 2010 & $10: 22: 58$ & 37.24 & 19.95 & 24 & 5.5 \\
3 Nov & 2010 & $18: 13: 11$ & 40.04 & 13.25 & 468 & 5.2 \\
7 July & 2011 & $19: 21: 46$ & 41.95 & 7.70 & 11 & 5.3 \\
19 July & 2011 & $07: 13: 12$ & 37.21 & 19.92 & 9 & 5.1 \\
27 Jan & 2012 & $14: 53: 13$ & 44.48 & 10.03 & 60 & 5.0 \\
20 May & 2012 & $02: 03: 52$ & 44.89 & 11.23 & 6 & 6.0 \\
20 May & 2012 & $13: 18: 02$ & 44.83 & 11.49 & 5 & 5.0 \\
29 May & 2012 & $07: 00: 03$ & 44.85 & 11.09 & 10 & 5.8 \\
29 May & 2012 & $10: 55: 57$ & 44.89 & 11.01 & 7 & 5.5 \\
29 May & 2012 & $11: 00: 25$ & 44.87 & 10.95 & 10 & 5.1 \\
3 June & 2012 & $19: 20: 43$ & 44.90 & 10.94 & 9 & 5.1 \\
25 Oct & 2012 & $23: 05: 24$ & 39.88 & 16.01 & 6 & 5.3 \\
21 June & 2013 & $10: 33: 59$ & 44.22 & 10.11 & 10 & 5.2 \\
29 Dec & 2013 & $17: 08: 43$ & 41.37 & 14.44 & 10 & 5.3 \\
\hline
\end{tabular}

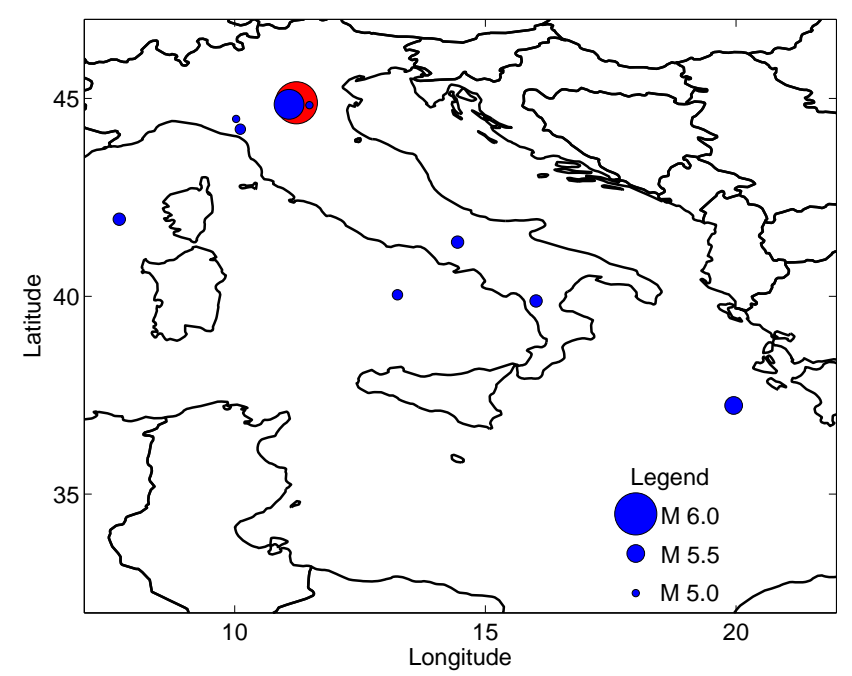

Figure 2. Map showing locations of magnitude $M \geq 5$ earthquakes listed in Table 2 that occurred in and near Italy (lat. $35-48^{\circ} \mathrm{N}$, long. 6-20 E) during 2010-2013. The red circle indicates the location of the 20 May 2012 earthquake that Guangmeng and Jie (2013) claim to have predicted. The areas of the circles are scaled with the approximate earthquake energy.

ilar to those that Guangmeng and Jie (2013) claim to have used to predict an earthquake, are frequently seen in Italy. In Fig. 1 we show 24 instances of linear-cloud formations in a 4year period of time. Outside of the $M 6.0$ earthquake event on 20 May 2012, and its subsequent aftershocks, it is difficult to imagine how the smaller earthquakes might be identified as being associated with a particular "linear"-cloud formation. Indeed, Guangmeng and Jie did not provide any specific criteria for classifying cloud formations as possible earthquake precursors, and there were many instances when it would be difficult to say whether or not a particular cloud formation was "linear", "semi-linear", "temporarily linear", etc. How, specifically, did Guangmeng and Jie manage to predict, even if only vaguely, the magnitude, location, and timing of an earthquake from their examination of cloud formations? We do not know since they have not told us.

Independent of the occurrence of earthquakes, and contrary to what is stated by Guangmeng and Jie (2013, p. 91), there is a simple meteorological explanation for the cause of the linear-cloud formations. Italy is a mountainous country; most prominently, the Apennine Mountains run along the length of the Italian peninsula. It is well-known that winds flowing towards mountains are lifted causing adiabatic cooling of air masses, and, if the relative humidity reaches $100 \%$, then "orographic" clouds form on the lee side of the range (e.g., Whiteman, 2000). Since mountain ranges are often aligned with mountain-bounding faults, orographic cloud formations can sometimes appear to be aligned with faults. And, since mountains are, for this discussion, unmoving and stationary, these orographic clouds are not advected away by the winds that are involved with their formation.

We note that the clouds in Fig. 1 are always located on the lee (eastern) side of the Apennine range when the wind flows from the southwest. With respect to the prediction of Guangmeng and Jie (2013), the linear-cloud formation for 22 April 2012 runs parallel to the NW-SE Apennine mountains, a tectonic region characterized by NE-SW extension and normal faulting. But the M6.0 earthquake on 20 May 2012 that they claim to have predicted occurred in the Po Valley in northern Italy, a tectonic region characterized N-S compression which produces E-W reverse faulting. While, ultimately, the Apennine Mountains and the Po Valley are related to each other through larger-scale regional plate tectonics, Guangmeng and Jie (2013) do not explain how a precursory linear-cloud formation that they identify over one part of Italy could, in practical terms, be related to an earthquake in a distinctively different part of Italy. We believe that the linear-cloud formation identified by Guang- 


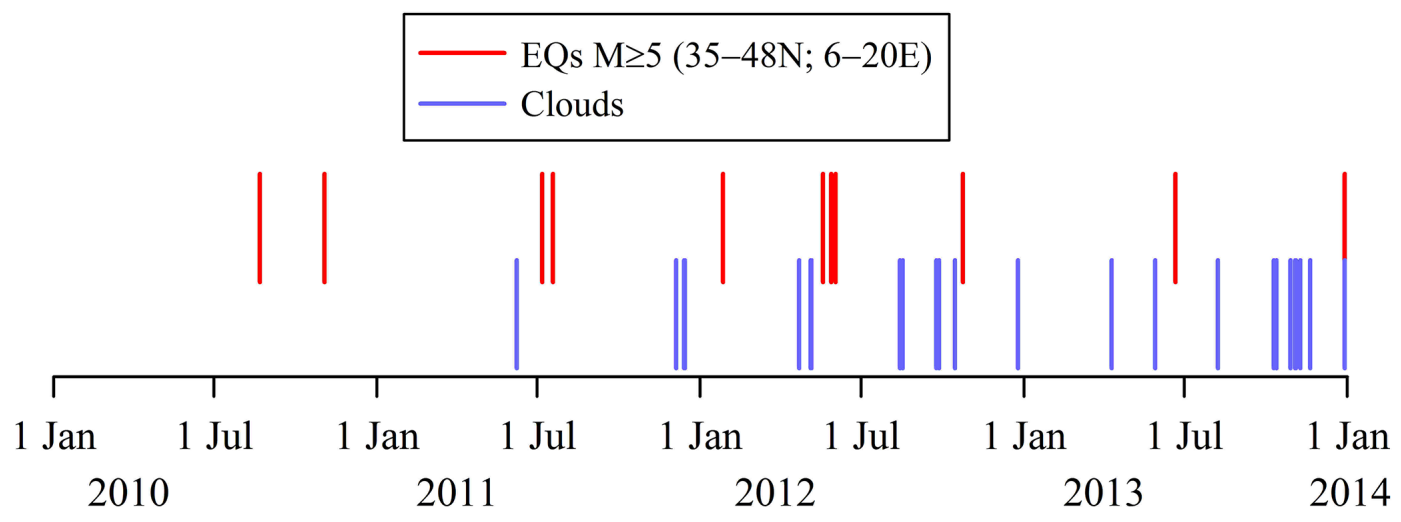

Figure 3. Time series of instances of linear-cloud formations and earthquake occurrences in and near Italy (lat. 35-48 $\mathrm{N}$, long. 6-20 $\mathrm{E}$ ) during 2010-2013.

meng and Jie (2013) and the other linear-cloud formations seen in Fig. 1 are simply orographic clouds, and, thus, unrelated to the earthquakes. That we have not been able to identify distinctive linear-cloud formations during January 2010 May 2011 in Fig. 1 is possibly just the result of variable atmospheric conditions that happened not to be conducive to orographic cloud formation during this time, even though there were actually two earthquakes during this time in the list given in Table 2 .

Signals identified as possibly precursory might have alternative causes that are unrelated to the earthquake process. Thus, when examining reports of earthquake precursors, it is important to determine if effects similar to the possible precursors are also observed during earthquakes (Park et al., 1993). Since the major energy is released during the earthquake, and not before the earthquake, if co-seismic changes do not occur, it is unlikely that the cloud formations have any physical relationship with the earthquake. Our analysis shows no evidence of co-seismic instances of cloud formations. Indeed, only one of the earthquakes listed in Table 2 (M5.3 on 29 December 2013) was accompanied on the same day by an instance of a cloud formation. And we note that the time of this earthquake was approximately $13 \mathrm{~h}$ after the cloud formation disappeared. The lack of co-seismic instances of cloud formation suggests that the reports of clouds by Guangmeng and Jie (2013) are unrelated to the earthquakes.

To objectively evaluate an earthquake-prediction hypothesis, each individual prediction should be clearly stated in quantitative terms: (1) a magnitude that the predicted earthquake is expected to exceed, (2) a specified range of epicenter geographic coordinates and hypocenter depth, and (3) a specified time window in which the earthquake can be expected to occur. To obtain confidence in the statistical significance of a prediction hypothesis, one that is based on the observation of possible precursory phenomena, an alternative null hypothesis of a random relationship between the possible precursory phenomena and earthquake occurrence should first be dismissed. This can be done using compilations of predictions that have been made prospectively of future earthquake occurrences. On the other hand, a prediction hypothesis can be dismissed with retrospective analysis of observations we already have of possible precursory phenomena and earthquakes that have already occurred (e.g., Love and Thomas, 2013, Sect. 2). If the hypothesis cannot predict past earthquakes, then there is no reason to expect that it can predict them in the future.

With that understanding, then, we perform a simple retrospective examination of the time statistics of the occurrence of the earthquakes listed in Table 2 and the linear-cloud formations listed in Table 1. As a null hypothesis we consider a uniform distribution in time. A simple Kuiper test (Press et al., 1996, Sect. 14.3) reveals that the earthquake list would not be a likely realization from a uniform distribution in time, $p=0.0239$. However, if we "decluster" the list, removing aftershock events occurring near and after the 20 May 2012 M6.0 event, then the Kuiper test reveals that the remaining events would have a high probability of being realized from a uniform distribution, $p=0.8951$. In contrast, the occurrence list of linear-cloud formations would not be a likely realization from a uniform distribution, $p=0.0015$. If we decluster this list by removing linear-cloud formations seen on consecutive days, the probability is still small, $p=0.0054$.

Next, we use the Kuiper test (for two separate data sets) to directly test the null hypothesis that the earthquake and linear-cloud lists might be realizations from the same statistical distribution. For non-declustered data, $p=0.2067$, meaning that there is a $20 \%$ probability that the data are realizations from the same distribution. This is not especially compelling if one is seeking to identify a statistical correlation. For declustered data, $p=0.0506$, which is not compelling at all for the existence of a correlation. We note that this statistical analysis agrees with what is shown in Fig. 3; there is no clear relationship between cloud formations and earthquake occurrence. Sometimes instances of linear-cloud formations seem to precede earthquake occurrences by days to months, 
and at other times no cloud formations occur prior to earthquakes.

One might reasonably conclude from this simple and straightforward examination of the data that linear-cloud formation and the occurrence of earthquakes are not evidently related to each other in a statistical sense over the latitudelongitude region we have selected. We imagine that Guangmeng and Jie might feel differently. If they do, then they need to clearly state the statistical relationship that they expect to exist between linear-cloud formations and earthquake occurrence. They have not yet done that. And, until they do, the rest of the geophysical community cannot test their hypothesis against future data.

Although Guangmeng and Jie (2013) report a few successful earthquake predictions, we note that they do not mention any unsuccessful predictions. Have all of their predictions been a success? We do not know since they have not told us. Reporting only successful predictions (not reporting all unsuccessful predictions) leads to what is sometimes called "publication bias" in which unsuccessful predictions are simply not published, or "file drawer bias" in which unsuccessful predictions are simply "filed away" and not seen again (e.g., Boslaugh, 2013, p. 462). Until Guangmeng and Jie report all their predictions, successful and unsuccessful, until each prediction is expressed in quantitatively specific terms, and until these predictions are objectively recorded before the predicted earthquake occurrence, then there is no way for the rest of the scientific community to evaluate the validity of their results. For now, we are skeptical of the validity of the claim by Guangmeng and Jie (2013) that they have managed to predict any earthquakes. And, in the spirit of the timetested scientific method, we encourage Guangmeng and Jie to scrutinize the validity of their own results.

\section{The Supplement related to this article is available online at doi:10.5194/nhess-15-1061-2015-supplement.}

Acknowledgements. We thank W. D. Barnhart, C. A. Finn, G. Guangmeng, J. McCarthy, and E. J. Rigler for reading a draft manuscript. We thank Marco Verdecchia of L'Aquila University, Italy for helpful discussions. This work was supported by the USGS Geomagnetism Program and the USGS Earthquake Hazards Program through external research grants G11AP20177 and G15AP00071 to JNT. We thank SAT24 (www.sat24.com) for permission to use their satellite images. Any use of trade, product, or firm names is for descriptive purposes only and does not imply endorsement by the US Government.

Edited by: B. D. Malamud

Reviewed by: two anonymous referees

\section{References}

Boslaugh, S.: Statistics in a Nutshell, O'Reilly Media, Sebastopol, CA, 2013.

Freund, F. T., Kulahci, I., Cyr, G., Ling, J., Winnick, M., TregloanReed, J., and Freund, M. M.: Air ionization at rock surfaces and pre-earthquake signals, J. Atmos. Sol.-Terrest. Phys., 71, 18241834, doi:10.1016/j.jastp.2009.07.013, 2009.

Guangmeng, G. and Jie, Y.: Three attempts of earthquake prediction with satellite cloud images, Nat. Hazards Earth Syst. Sci., 13, 91-95, doi:10.5194/nhess-13-91-2013, 2013.

Guo, G. M. and Wang, B.: Cloud anomaly before Iran earthquake, Int. J. Remote Sens., 29, 1921-1928, doi:10.1080/01431160701373762, 2008.

Harrison, R. G., Aplin, K. L., and Rycroft, M. J.: Brief Communication: Earthquake-cloud coupling through the global atmospheric electric circuit, Nat. Hazards Earth Syst. Sci., 14, 773777, doi:10.5194/nhess-14-773-2014, 2014.

Love, J. J. and Thomas, J. N.: Insignificant solar-terrestrial triggering of earthquakes, Geophys. Res. Lett., 40, 1165-1170, doi:10.1002/grl.50211, 2013.

Park, S. K., Johnston, M. J. S., Madden, T. R., Morgan F. D., and Morrison, H. F.: Electromagnetic precursors to earthquakes in the ULF bands: a review of observations and mechanisms, Rev. Geophys., 31, 117-132, doi: 10.1029/93RG00820, 1993.

Press, W. H., Teukolsky, S. A., Vetterling, W. T., and Flannery, B. P.: Numerical Recipes, Cambridge Univ. Press, Cambridge, UK, 1996.

Shou, Z. H.: Earthquake clouds, a reliable precursor, Science \& Utopya, 64, 53-57, 1999 (in Turkish).

Shou, Z. H.: Earthquake vapor, a reliable precursor, in: Earthquake Prediction, edited by: Mukherjee, S., 21-51, CRC Press, Boca Raton, FL, 2006.

Whiteman, C. D.: Mountain Meteorology: Fundamentals and Applications, Oxford University Press, New York, NY, 2000.

Wu, L. X., Li, J. P., and Liu, S. J.: Space observed two abnormal linear clouds before Wenchuan earthquake, 3rdIASME/WSEAS Int. Conf. Geol. Seismol., Cambridge, UK, 138-143, 2009. 